\title{
Interpretación y Representación de las Onomatopeyas en el Lenguaje Escrito al Momento de Traducir
}

\author{
Interpretation and Representation of Onomatopoeias in the Written \\ Language when Translating
}

Claudia Cristel Salaya Custodio*

Eleazar Morales Vázquez ${ }^{* *}$

\begin{abstract}
* Claudia Cristel Salaya Custodio profesora de inglés de nivel básico en el sector privado en la escuela "International Compu" desde el de 2016. Además, estudiante de Licenciatura en Idiomas del área terminal de Traducción e Interpretación. Áreas de interés académico y de investigación: el papel de la cultura en la traducción e interpretación, la traducción e interpretación de textos científicos y técnicos, la enseñanza del idioma inglés en el nivel primario.

** Eleazar Morales Vázquez, profesor investigador de tiempo completo de la Universidad Juárez Autónoma de Tabasco. Egresado de la primera generación de la Maestría en Enseñanzas del Idioma Inglés por la UJAT en 2012. Áreas de interés académico y de investigación: La evaluación formativa en la enseñanza de una segunda lengua, la retroalimentación en la enseñanza de una segunda lengua, los factores afectivos en el proceso de enseñanza de una segunda lengua.
\end{abstract}

\section{RESUMEN}

El propósito de este artículo es analizar el proceso de traducción e interpretación de las onomatopeyas del inglés al español. De la misma manera, se busca describir la carga cultural que estos sonidos tienen al momento de su traducción. Para el desarrollo de este trabajo investigativo, se recupera la sociolingüística y la pragmática fónica desde un enfoque cualitativo y los documentos en los cuales se ha fundamentado, provinieron de fuentes verídicas y comprobables. El análisis de las traducciones de las onomatopeyas se realizó a través del discurso oral y escrito. Se aplicó un ejercicio de traducción de onomatopeyas a estudiantes de la materia de Traducción de la Licenciatura en Idiomas. Los resultados muestran que la traducción e interpretación de las onomatopeyas dependen totalmente del contexto cultural donde éstas se producen; la técnica más usada en la traducción de las onomatopeyas es la adaptación debido a que la fiabilidad del proceso de traducción e interpretación depende totalmente de los aspectos culturales de estos sonidos.

Palabras Clave: Análisis del Discurso, Comics, Factores Culturales, Sociolingüística, Traducción

\section{ABSTRACT}

The purpose of this article is to analyze the process of translation and interpretation of the onomatopoeias from English to Spanish. Likewise, it seeks to analyze the cultural load that onomatopoeias have when they are being translated. To carry out this research project, the sociolinguistic and the sound pragmatic were taken into account from a qualitative approach perspective and the analyzed documents were taken from true and verifiable sources. The analysis of the translation of onomatopoeias was made through an analysis of the oral and written discourse. A translation exercise of onomatopoeia was applied to students of the subject of Translation of the Languages Degree. The results show that the translation and interpretation of the onomatopoeias are entirely dependent on the cultural context where they are uttered; the most used technique to translate onomatopoeias is the adaptation because the reliability of the process of translation e interpretation depends totally on the cultural aspects of these sounds.

Key words: Discourse Analysis, Comics, Linguistic Differences, Cultural Factors, Sociolinguist, Translation

\section{INTRODUCCIÓN}

En este trabajo se describe una problemática que ha sido poco abordada, es decir, cómo se interpretan y representan las onomatopeyas en el lenguaje escrito, cómo se traducen éstas del inglés al español y por qué son más importantes de lo que parecen. Esta investigación pretende resaltar la importancia de la carga cultural que tienen las onomatopeyas y el proceso de traducción de éstas, algo que el traductor tiene que considerar al traducir un comic o un cuento; la traducción de las onomatopeyas es importante porque éstas impactan al lector y le dan un sentido dramático a la historia y hace que disfrute la lectura. Además, debe tenerse en cuenta que, las onomatopeyas llevan un proceso de lexicalización que influye en la manera de cómo se traducirá y que muy pocos traductores conocen y toman en cuenta. 
Perspectivas Docentes 64

Interpretación y Representación de las Onomatopeyas en el Lenguaje Escrito al Momento de Traducir

Interpretation and Representation of Onomatopoeias in the Written Language when Translating

Claudia Cristel Salaya Custodio / Eleazar Morales Vázquez

En el análisis de esta problemática se describen el objetivo, justificación y estado del conocimiento en donde se recopilan todos los autores relevantes de esta investigación. Para demostrar la importancia de las onomatopeyas en el proceso de traducción se describen los antecedentes, es decir, las teorías de los orígenes del lenguaje, indicando cuál fue su contribución a las onomatopeyas y a su formación. De igual manera, se explica en qué consisten las onomatopeyas, su proceso de formación, qué necesita sonido natural para ser llamado onomatopeya y la gran influencia que la cultura tiene en este proceso. Lo siguiente que se analiza es el proceso de traducción de la onomatopeya y cómo también en esta categoría la cultura juega un papel muy importante para lograr este proceso y, finalmente, se describe la metodología utilizada para realizar la investigación.

\section{PROBLEMATIZACIÓN Y PREGUNTAS DE INVES- TIGACIÓN}

En cada idioma la representación de los sonidos naturales es distinta. No existen muchos trabajos sobre este tema puesto que no fue sino hasta el siglo XIX que las onomatopeyas comenzaron a representarse en el lenguaje escrito para evocar un sentimiento. Actualmente en donde existen más expresiones es en los comics, ya sea del inglés al español o del japonés al español. Las onomatopeyas son representadas de distintas maneras en cada país, en cada idioma e incluso en cada persona del mismo idioma, porque llevan un proceso de formación que es individual, no es solo la imitación de un sonido natural, sino cómo lo interpreta cada hablante y lo reproduce. Gestualidad y entonación que acompañan a la onomatopeya refuerzan o dan sentido a la expresión, por este motivo, la lingüística no ha podido clasificarlas, ya que estos sonidos naturales son culturales, es muy difícil para los traductores poder traducirlos y transmitir el sentimiento original.

No todos los sonidos naturales pueden ser considerados como onomatopeyas, solo unos cuantos, ya que cada idioma tiene sus pautas para la aceptación de éstas. Si todas las onomatopeyas fuesen aceptadas causarían un gran desequilibrio en el idioma (desbordamiento verbal). Es de allí de donde surgen estas preguntas:

- ¿Cómo se podrían traducir las onomatopeyas de un idioma a otro para que sean comprensibles de la lengua origen a la lengua meta?
- ¿Qué reglas deben seguirse?

- ¿Es la cultura un factor importante a considerar en el proceso de traducción e interpretación de las onomatopeyas?

A partir de esas interrogantes surge el objetivo general del estudio que consiste en analizar y describir el proceso de traducción e interpretación de las onomatopeyas del inglés al español. A la vez surgieron algunos propósitos específicos tales como: ampliar el conocimiento, principalmente de los traductores, en las onomatopeyas; profundizar en el uso de las onomatopeyas; y, resaltar la importancia de la cultura al momento de traducirlas.

\section{IMPORTANCIA DEL OBJETO DE ESTUDIO}

Es necesario explicar y destacar la importancia que las onomatopeyas tienen en el lenguaje escrito. Merabian (s.f.) plantea que al momento de comunicarse con otra persona las palabras cuentan en un 7\%, el tono de voz un $38 \%$ y la expresión del cuerpo y la cara 55\%. Como el lenguaje es arbitrario, rara vez aceptan sonidos como parte del lenguaje correcto, la gran mayoría no tiene o no entra en una categoría gramatical, ya que tienen tantos significados como hablantes, porque el significado que cada uno le otorgue va a depender casi en su totalidad del contexto en el que estén.

Por lo tanto, este trabajo de investigación busca explicar con más claridad el uso de estos sonidos y por qué sí es importante en la comunicación y por la diferencia de estos en cada idioma y hablante. De acuerdo a Jiménez (2010), el lenguaje es la capacidad que posee el hombre de comunicarse con los demás a través de sonidos a los que otorga un significado. Es por esto que cada hablante interpreta y reproduce los sonidos de diferente manera. Hay estudios muy vagos sobre las onomatopeyas y estos son pocos. Por esta razón es necesario analizar y describir la relevancia de estos sonidos. Según Buron (s.f.) el proceso de traducción de las onomatopeyas es muy difícil ya que éstas son hechos totalmente culturales. Por lo tanto, se considera importante que pudiera existir un diccionario en línea con las onomatopeyas más comunes, que se actualice de manera constante por los usuarios, podría ser de gran utilidad y valía para los traductores. 
Perspectivas Docentes 64

Interpretación y Representación de las Onomatopeyas en el Lenguaje Escrito al Momento de Traducir

Interpretation and Representation of Onomatopoeias in the Written Language when Translating

Claudia Cristel Salaya Custodio / Eleazar Morales Vázquez

\section{ESTADO DEL CONOCIMIENTO}

"El lenguaje es la capacidad que posee el hombre de comunicarse con los demás a través de sonidos a los que otorga un significado" (Jiménez, 2007, p. 1). He aquí la importancia de explicar con más claridad la formación de las onomatopeyas, porque de éstas se origina el lenguaje tal y como lo conocemos hoy. La idea de Jespersen (citado en Yule, 1998) de que el lenguaje humano surgió cuando los humanos disfrutaban realmente de la vida, es una de las especulaciones más atractivas sobre el origen del lenguaje, pero no es más que otra hipótesis entre muchas.

El lenguaje que nosotros conocemos es arbitrario (la escritura alfabética), porque los sonidos no se parecen a lo que representan, en cambio en la prehistoria las cosas se representaban con logogramas (en el caso de los sumerios) pictogramas e ideogramas (en el caso de los chinos) o jeroglíicos (en el caso de los egipcios) e incluso aún existen lenguas que no han desarrollado la escritura. "La relación natural entre el significado y el significante nace de la propia arbitrariedad de las palabras" (Jiménez, 2007, p. 6).

Yule (1998), en su libro El lenguaje, plantea diversas teorías que especulan sobre los orígenes del lenguaje, pero las que más cercanas a lo que se quiere explicar son las siguientes:

La hipótesis del sonido natural: La idea es que las palabras primitivas podrían haber sido imitaciones de los sonidos naturales que los hombres y mujeres primitivos oían a su alrededor. [...] El hecho de que todas las lenguas modernas tengan algunas palabras con pronunciaciones que parecen imitar los sonidos de la naturaleza podría ser utilizado como argumento a favor de esta teoría (p.12).

La teoría del origen oral-gestual: Propone una conexión demasiado específica entre la gestualidad y la física. Esta teoría afirma que, originalmente, se habría desarrollado un conjunto de gestos físicos como medio de comunicación. Después habrían aparecido los gestos orales, concretamente los hechos con la boca, en los que los movimientos de la lengua, labios y demás órganos, se reconocerían de acuerdo a patrones de movimientos similares (p.14).
Se podría decir que este es el origen de muchos lenguajes. En el mundo existen entre 3,000 y 5,000 lenguas y cada una de estas tiene sus propias representaciones de sonidos naturales (onomatopeyas). "La onomatopeya al contrario que la imitación no lingüística o reproducción, se integra en el sistema fonológico de la lengua considerada, aunque su combinación difiera un poco de las combinaciones más frecuentes de aquella" (Torres y Barbeira, 2003, p. 4). La onomatopeya tiene un proceso de formación de cuatro fases: Audición, interpretación, alfabetización y lexicalización. Bueno (2009) plantea que de esta manera solo algunas pueden ser aceptadas, ya que si todas fueran aceptadas crearían un gran desequilibrio en la lengua.

$\mathrm{Si}$, en un principio, las onomatopeyas surgen como simple imitación, de ruidos pertenecientes al campo de la física, su posterior evolución se muestra en diferentes soluciones: unas, no pasan de ser una mera imitación de sonidos sin más repercusión en el hábito lingüístico; otras, no alcanzan gran popularidad y extienden su radio de acción a los diferentes niveles culturales; unas terceras, sufren tal proceso de lexicalización que, aunque mantienen su vigor, han perdido buena parte de su valor imitativa (Bueno, 2009 p. 16).

Aunque los usuarios de la lengua son quienes la definen, no todo puede ser aceptado como correcto ya que si así fuera, cada quien tendría su propio código y el mensaje no se transmitiría, no habría comunicación, lo cual es el principal motivo del lenguaje.

En ocasiones, algunas personas nos sorprenden con el uso de alguna palabra de su propia invención. Nos damos cuenta que la palabra se ajusta a las posibilidades que da el sistema de la lengua, pero no está en la norma, por lo que no la reconocemos como aceptada por el uso (Romeu, 2012, p. 71).

Las onomatopeyas son culturales, comunican sentimientos e impresiones emotivas 0 expresivas. Estos sonidos dependen mucho del contexto, no solo el cultural. Es muy difícil traducirlas y transmitir el sentimiento original porque no solo es la imitación de un sonido natural, sino de cómo lo interpreta cada hablante y de cómo lo reproduce porque llevan un proceso de formación que es individual. "La cultura es un ente estable que determina ontológicamente todos los fenómenos que acontecen en su seno al imprimirles una esencia compartida por todos ellos" (Marín, 2005, p.1) 
Perspectivas Docentes 64

Interpretación y Representación de las Onomatopeyas en el Lenguaje Escrito al Momento de Traducir

Interpretation and Representation of Onomatopoeias in the Written Language when Translating

Claudia Cristel Salaya Custodio / Eleazar Morales Vázquez

Hay otro tipo de expresiones como las onomatopeyas llamadas interjecciones, estas tienen una función muy similar puesto que nacen las onomatopeyas. Si bien la mayoría de las onomatopeyas son interjecciones, en cambio muchas de estas no son en absoluto de origen onomatopéyico. "Por ser unidades lingüísticas plenas, las onomatopeyas pueden lexicalizarse y entonces siguen las normas que rigen a los términos. El problema radica en conocer el origen de las nuevas creaciones para considerarlas simples interjecciones y/u onomatopeyas" (Buron, s.f. p.1). De la misma manera "... algunas interjecciones pueden pronunciarse incluso sin necesidad de estar dirigidas a un interlocutor ya que su uso puede tener como objetivo el mero hecho de expresar estados mentales del hablante sin necesidad de comunicarlos a los demás" (Torres, 2004, p. 117).

Este tipo de expresiones, ya sean onomatopeyas 0 interjecciones, pueden identificarse en los comics, en los tebeos 0 en la literatura, pero no antes del siglo XIIX. En la actualidad es más común encontrar estas expresiones en los comics o mangas (historietas japonesas) a pesar de que estas expresiones son comúnmente orales, excepto cuando las queremos plasmar. "Encontramos en el género del "comic" una cantera inagotable para la creación de nuevas interjecciones y de grafías novedosas para las ya existentes" (De la Cruz, 2009 , p. 10). Sin embargo, no basta con plasmarlas en un papel, porque solo leyéndolas no se entiende lo que se quiere decir, hace falta conocimiento sobre la cultura del texto que se esté leyendo y muchas de veces de ademanes y expresiones faciales y el contexto de la situación.

Si el traducir se identifica con la historia (traducción como transmisión cultural) asistiremos paradójicamente a la historia del hombre sin el hombre. Este tipo de supuesto pretende dar cuenta ciertamente de la dependencia histórica del sujeto respecto a su contexto histórico (respecto a su lenguaje), lo que resulta una posición crítica en principio razonable (Hernández, 2003 p. 4).

Si no se tiene un conocimiento amplio de la cultura del texto origen, no se puede transmitir el sentimiento adecuado al texto meta.

La fidelidad al texto debe pasar ante todo por el tamiz de un buen conocimiento de la cultura y un bagaje lingüístico intachable para no hablar sin ton ni son ni traducir dando pie a un rifirrafe de impropiedades (Buron, s.f. p. 2).
"Así como concibamos la cultura, así enfocaremos el proceso traslativo, pues todo método de traducción lleva implícito un determinado concepto de cultura." (Marín, 2005, p.3). Hay ocasiones en que las onomatopeyas no se pueden traducir tal y como son porque la cultura no lo permite, en ese caso se debe buscar una adecuación, algo que acerque al lector 0 al oyente hacia el sentimiento de la expresión original, aunque no sea la misma impresión. Esto sucede principalmente cuando las culturas son totalmente opuestas, por este motivo es muy difícil traducir dichas expresiones. Esta es la principal razón por la que el traductor debe estar preparado, informarse y conocer mucho sobre la cultura del texto y a la que va dirigida. El papel del traductor como sujeto silencioso o silenciado en el proceso, sigue siendo la tónica general de la teoría y la praxis traductológicas. "Hacer bien las cosas y que no se note" constituye un tipo de ideal ya en sí mismo paradójico de dicha praxis para el sujeto, factor humano, que la lleva a término (Marín, 2005, p. 6).

¿Qué son las Onomatopeyas y cuál es su importancia?

"El lenguaje es la capacidad que posee el hombre de comunicarse con los demás a través de sonidos a los que otorga un significado" (Jiménez, 2010, p.1). Las onomatopeyas son sonidos naturales de los seres humanos y el inicio de la legua como comunicación, de éstas se origina el lenguaje tal y como lo conocemos hoy. Una onomatopeya es una palabra formada por imitación de un sonido, ruido o incluso un fenómeno visual, con el que también está vinculada semánticamente. También se llama así la propia imitación, así como la figura retórica que consiste en el uso de onomatopeyas (Wikilengua, 2013, párr. $1)$.

Debido a que el lenguaje es arbitrario rara vez acepta sonidos como parte del lenguaje correcto, su gran mayoría no tiene o no entra en una categoría gramatical, ya que tiene tantos significados como hablantes haya, porque el significado que cada hablante le otorgue va a depender casi en su totalidad del contexto en el que estén, puesto que cada persona lo interpreta de manera diferente. Las onomatopeyas son una parte del lenguaje no arbitrario que nos sirve para expresar lo que sentimos de una manera más fiel al sonido que escuchamos.

Tal y como defendió Saussure en su curso de lingüística general, la lengua es un sistema de signos y estos son casi todos arbitrarios; es decir, solo existen ciertos signos que no obedecen a esta característica. La no 
Perspectivas Docentes 64

Interpretación y Representación de las Onomatopeyas en el Lenguaje Escrito al Momento de Traducir

Interpretation and Representation of Onomatopoeias in the Written Language when Translating

Claudia Cristel Salaya Custodio / Eleazar Morales Vázquez

arbitrariedad del lenguaje aparece representada en: a) las onomatopeyas; b) algunas palabras compuestas; y c) aquellos topónimos en los que el termino hace referencia a las características del lugar que designa (Jiménez, 2010, p. 1).

Como menciona Jiménez (2007), las onomatopeyas son parte de la gramática que no es arbitraria, aunque para ser llamadas onomatopeyas deben pasar por una serie de fases. Aun así, no todos los lingüistas consideran a las onomatopeyas como parte de la gramática. Según Torres (2004) la onomatopeya no es exactamente una simple imitación de los sonidos naturales, sino la conversión de éstas en palabras con una alfabetización de los sonidos naturales ajustados al alfabeto de cada idioma. De manera general las onomatopeyas fueron el medio, no arbitrario, por el que el hombre comenzó a comunicarse, son los sonidos tales como el ronronear de un gato (prr-prrr), el llanto (bua-bua!) o el sonido de un timbre (ring-ring).

\section{PROCESO DE FORMACIÓN}

Las onomatopeyas no deben ser confundidas con las interjecciones puesto que cada una tiene su propio proceso de formación o lexicalización. Las interjecciones tienen una función muy similar puesto que de ellas nacen las onomatopeyas. Aunque muchos autores las tienen en la misma categoría que éstas. Su proceso de formación es lo que las hace diferente.

A pesar de que, en la literatura sobre el tema, la onomatopeya se suele considerar como un tipo de interjección, existe, en nuestra opinión, una serie de criterios semánticos y pragmáticos que aconsejan un tratamiento diferente para cada uno de estos elementos (Torres y Barbeira, 2003, p.3).

"Por ser unidades lingüísticas plenas, las onomatopeyas pueden lexicalizarse y entonces siguen las normas que rigen a los términos. El problema radica en conocer el origen de las nuevas creaciones para considerarlas simples interjecciones y/u onomatopeyas". (Buron, s.f. p. 1). Por lo tanto, puede mencionarse que:

La interjección codifica información procedimental y contribuye, según su tipo, a la construcción de explicaturas de alto nivel 0 de implicaturas fáticas, mientras que la onomatopeya hace referencia a estructuras conceptuales complejas y contribuye a la proposición expresada por un enunciado (Torres y Barbeira, 2003, p. 363).

Según Bueno (2009), el proceso de formación de las onomatopeyas tiene las siguientes fases:

Audición: es la primera de todas y la única exclusivamente fisiológica. Es una audición múltiple -habrá tantas como oyentes haya - que depende de las condiciones auditivas propias de cada oyente y, además, del grado de atención que éste le preste al sonido en cada momento.

Interpretación: tras la audición viene el proceso por el cual el oyente trata de imitar no el sonido en sí, sino la sensación fónica que el ruido en cuestión produce en él. Esta libertad interpretativa nos explica la inexistencia de una unidad onomatopéyica, aunque sí la haya de sonido. La variedad de onomatopeyas como consecuencia de diferentes variantes interpretativas ha dado lugar a varias ideas erróneas.

Alfabetización: el siguiente paso es la adaptación del sonido interpretado al alfabeto humano, una vez que la onomatopeya es aceptada como elemento del idioma. Para muchos una interjección deja de considerarse "grito instintivo» y se le concede el estatus de "palabra» cuando aparece como entrada en un diccionario. Por esta razón, no es posible hablar de interjecciones sin matizar que no todas se encuentran en el mismo grado de integración en el sistema de la lengua. Algunas tienen una tradición lingüística larga y una etimología; por ejemplo: ¡Alas!, ¡Hey!, ¡Pshaw!, ¡Ow!, etc. Otras — ¡Hm!, ¡Grrr!, ¡Tch! - están menos lexicalizadas, sin dejar por ello de formar parte de la lengua.

Sin duda, las onomatopeyas surgen como una mera imitación de los sonidos comunes o naturales, actualmente sabemos que si pasan por un proceso de lexicalización son oficialmente aceptadas y una vez ya lexicalizada la onomatopeya puede convertirse en un sustantivo, adjetivo, etc. Sin embargo, muchas de estas onomatopeyas no pasan de ser eso y no son aceptadas en la gramática.

Se puede decirque las onomatopeyas son un tema más complejo de lo que parece, por ser desconocido y difícil de comprender, incluso para los lingüistas, ya que las onomatopeyas podrían ser confundidas con interjecciones; llevan un proceso de lexicalización para poder ser aceptadas, ya que no cualquier sonido puede ser considerado onomatopeya. 
Perspectivas Docentes 64

Interpretación y Representación de las Onomatopeyas en el Lenguaje Escrito al Momento de Traducir

Interpretation and Representation of Onomatopoeias in the Written Language when Translating

Claudia Cristel Salaya Custodio / Eleazar Morales Vázquez

\section{LAS ONOMATOPEYAS Y LA CULTURA}

"La cultura es un ente estable que determina ontológicamente todos los fenómenos que acontecen en su seno al imprimirles una esencia compartida por todos ellos." (Marín, 2005, p.1). Las onomatopeyas son culturales y en este sentido, la cultura es un tema muy importante en muchas ramas de la lingüística, porque los idiomas son cultura, e incluso en el mismo idioma puede haber muchas maneras de interpretar una misma cosa. Esto se debe al contexto social de cada hablante y uno de los elementos que más depende de la cultura son las onomatopeyas, ya que son subjetivas y dependen totalmente de la interpretación de cada sujeto.

Por lo tanto, si no se tiene un conocimiento amplio de la cultura del texto origen no se puede transmitir el sentimiento adecuado al texto meta; cuando se dificulta traducir una oración o expresión se basa en la cultura que será la que otorgue el sentido no literal de dicha expresión. Por ello, se puede estar de acuerdo con Marín (2005) en la consideración de la cultura como unidad de traducción. "Así como concibamos la cultura, así enfocaremos el proceso traslativo, pues todo método de traducción lleva implícito un determinado concepto de cultura." (Marín, 2005, p. 75) Muchas veces las onomatopeyas no se pueden traducir tal y como son, porque la cultura no lo permite, en tal caso se debe buscar una adecuación, algo que haga acercar al lector 0 al oyente al sentimiento de la expresión original, aunque no sea la misma impresión. Esto sucede cuando las culturas son totalmente opuestas, por este motivo es muy difícil traducir dichas expresiones.

Como ya se había mencionado, la manera en que las onomatopeyas sean representadas dependerá de cómo las interprete cada hablante y así mismo la interpretación de éstas dependerá de la cultura, costumbres, idioma y contexto social del hablante. Porque, aunque el sonido sea el mismo, la manera en que conciba este será diferente.

Dado que los sistemas gramaticales de cada lengua son diferentes, es lógico que los elementos de carácter onomatopéyicos varíen notoriamente de una lengua a otra. Esta propuesta interpretativa de la onomatopeya se fundamenta, como vemos, en sus aspecto fonéticos, morfológicos y sintácticos (Torres y Barbeira, 2003, p.4).

Un claro ejemplo de esto es como se representa el sonido de la risa en cada país.
Jajaja (risa en español):

Hahaha (risa en inglés)

Héhéhé (risa en francés)

5555 (risa en tailandes)

Kkkkk (risa en portugués)

\section{USO ORAL Y ESCRITO DE LA ONOMATOPEYA}

Las onomatopeyas son mayormente de sentido oral pero cuando estas expresiones orales se quieren imitar, se plasman en papel y es en los comics, en los tebeos 0 en la literatura en donde se pueden encontrarse este tipo de expresiones, ya sean onomatopeyas o interjecciones. En la actualidad, es más común encontrar estas expresiones en los comics o mangas (historietas japonesas) a pesar de que estas expresiones son más comúnmente orales, excepto cuando las queremos plasmar. Las onomatopeyas también de identifican en libros infantiles, porque son usadas para llamar la atención del niño y hacer la historia mucho más interesante. Sin embargo, no basta con plasmarlas en un papel, porque solo leyéndolas no se entiende lo que se quiere decir, hace falta conocimiento sobre la cultura del texto que se esté leyendo y muchas veces, de ademanes y expresiones faciales y el contexto de la situación.

En la lengua oral la prosodemia y sobre todo los elementos paralingüísticos ligados a la voz, es decir, «al modo de hablar» (entonación, énfasis, ritmo, timbre, velocidad, pausas, mímica, gestos) son tan relevantes como lo puede ser, en el texto escrito, el tipo de material sobre el que se escribe, el formato, el carácter, etc. (Torres, 2004, p. 118).

Por ello, traducir las onomatopeyas y que se interprete el sentimiento original, es muy difícil porque son totalmente culturales. Sobre todo, en el lenguaje escrito, ya que el contexto debe estar muy bien planteado para que las onomatopeyas adquieran un sentido lógico, mientras que en el lenguaje oral el contexto no debe ser explicado porque se está en él y el sujeto asume el significado ya que tiene los elementos a su alrededor y la interpretación de las onomatopeyas debería ser más precisa, ya que facilita la canalización de su expresión, incluso cuando su contexto cultural es diferente al de su origen; también desde hace un tiempo las onomatopeyas se están usando en el teatro, porque facilita la comprensión de lo que se quiere expresar. 


\section{METODOLOGÍA}

El objetivo de esta investigación es analizar el proceso de traducción y la interpretación de las onomatopeyas del inglés al español, saber qué tan importante es el conocimiento de la cultura para traducirlas y ampliar el conocimiento de éstas, para que sea más fácil para los traductores interpretarlas.

Las variables de este estudio son la interpretación y la representación de las onomatopeyas en el lenguaje oral y escrito al momento de traducir, las cuales buscan mostrar cómo las personas interpretan las onomatopeyas. Es necesario conocer, a partir de la interpretación, cómo las expresan de manera oral y las representan de manera escrita al momento de realizar una traducción, cómo deberían interpretarlas correctamente, saber qué herramientas y conocimientos son necesarios para lograr traducirlas. De la misma manera, se busca observar los aspectos que debe considerar el traductor al momento de hacer la traducción. Además, saber qué tan importante es el conocimiento de la cultura, así como el conocimiento de las técnicas de traducción para llevar a cabo el proceso de traducción.

Esta investigación se lleva a cabo tomando en cuenta la sociolingüística y la pragmática fónica desde un enfoque cualitativo por el cual se buscaron documentos con bases sólidas, integra información verídica y comprobable, con autores que justifican su investigación, con la sociolingüística como base y también la pragmática fónica. Pues las onomatopeyas son vistas desde una perspectiva sociocultural y su formación depende de las reglas gramaticales. Con un diseño de análisis de los discursos en el cual se analicen el proceso de traducción tanto en el lenguaje oral como en el escrito y la manera en que cada persona de distinta cultura y concepciones sociales lo interpreta.

La técnica aplicada en esta investigación fue la observación y la aplicación de un pequeño ejercicio. Se hizo observación tanto en campo como en textos. La observación en campo se llevó a efecto para comprobar la importancia que tiene la cultura en el proceso de interpretación y traducción de las onomatopeyas, la cual tuvo razón de ser en un grupo de la materia de Traducción a cargo de un profesor y traductor de la Licenciatura en Idiomas. El análisis de textos se llevó a cabo para conocer cómo estas reglas y conocimientos son aplicados a la hora de traducirlas y plasmarlas. La aplicación del ejercicio se hizo para comprobar si los traductores inexpertos o estudiantes de traducción saben cuál es la importancia de la cultura en las onomatopeyas.

\section{Resultados}

\section{V1 Interpretación de las onomatopeyas en el lenguaje oral.}

Las onomatopeyas se representan según su contexto social, cada cultura y cada persona de esa cultura interpreta los sonidos dependiendo del contexto en el que se desarrolló. Por esto se dice que las onomatopeyas dependen totalmente de la cultura y es el único elemento de la gramática que no es arbitraria porque son fieles al sonido que representan.

V2 Representación de las onomatopeyas en el lenguaje escrito.

La representación de las onomatopeyas depende de la interpretación que el hablante le dé al sonido. Puede haber tantas representaciones como hablantes en el mundo.

V3 Traducción de las onomatopeyas del inglés al español en el lenguaje escrito (comics, cuentos).

La traducción de las onomatopeyas del inglés al español fue un poco complicada, ya que no hay muchas onomatopeyas en los comics estadounidense. Sin embargo, se encontraron documentos que fueron de mucha ayuda para analizar la traducción de las onomatopeyas. Aunque las onomatopeyas pudieran ser traducidas, en algunos comics actuales la traducción de las onomatopeyas es difícil porque tienen un formato difícil de rehacer, por lo que las onomatopeyas no se traducen por esta razón, no porque no tengan un equivalente.

V3 Influencia de la cultura en el proceso de traducción de las onomatopeyas.

La cultura es lo más importante para la creación de una onomatopeya, porque las onomatopeyas son totalmente culturales. Dependiendo del lugar, de la persona y de las condiciones que rodeen al sujeto es, como este, creará y representará la onomatopeya.

V4 Aplicación de técnicas en el proceso de traducción de las onomatopeyas

La técnica más usada al traducir una onomatopeya es la adaptación pues, como ya se ha mencionado antes, dependen totalmente de la cultura. 
Perspectivas Docentes 64

Interpretación y Representación de las Onomatopeyas en el Lenguaje Escrito al Momento de Traducir

Interpretation and Representation of Onomatopoeias in the Written Language when Translating

Claudia Cristel Salaya Custodio / Eleazar Morales Vázquez

\section{ANÁLISIS E INTERPRETACIÓN DE RESULTADOS}

El análisis de textos dio como resultado las distintas interpretaciones y traducciones que las personas, de distintas culturas y concepciones sociales le dieron a una misma onomatopeya, tales como la onomatopeya de llanto, que en inglés es, ¡"waahwaah!" y en español es “¡Buabua!”. Además de las distintas interpretaciones que cada cultura le da, las onomatopeyas pueden ser traducidas de idioma a idioma, en este caso del inglés al español, un claro ejemplo está en la historieta de Garfield, ique para el sonido de golpe en inglés es "snack!" y traducida al español queda como "Plaf!". En este caso, la onomatopeya sí tenía un equivalente en español, pero no siempre la tiene o incluso, a veces no es necesario traducirlas porque el lector está adaptado a las onomatopeyas del idioma inglés. Pero hay ocasiones en las que no existe el equivalente de la onomatopeya, o como ya se mencionaba antes, no es necesario traducirlas porque se entienden perfectamente. Sin embargo, aunque exista un equivalente o sea necesario traducirla, la onomatopeya no puede ser traducida debido al formato del comic o historieta, como es el caso de los comics actuales, en este caso Civil War II\#1, en el cual la onomatopeya no se traduce en ningún momento, puesto que el formato del comic es muy elaborado, y reproducir nuevamente el estilo de dibujo de la onomatopeya es prácticamente imposible. Esto algo que influye en que los lectores están más adaptados a las onomatopeyas de habla inglesa que a las de su propio idioma. Esto hace que la traducción de las onomatopeyas sea menos frecuente.

Por otro lado, la observación en un grupo de alumnos al cual el profesor y traductor le imparte la materia de Traducción en la Universidad Juárez Autónoma de Tabasco, se pudo identificar que tienen poco conocimiento previo e interés sobre este tema, ya que al no tener muchas referencias en su entorno común, muchos no saben qué son las onomatopeyas y mucho menos en qué radica su importancia.

Mientras el profesor explicaba dicho tema los alumnos reían y algunos participaban activamente, mientras que otros parecían confusos, hasta que el profesor comenzó a ejemplificar y ellos empezaron a relacionar el término con las onomatopeyas. Aunque la mayoría de las veces tampoco tenían el equivalente de la onomatopeya. El profesor les explicaba a sus alumnos la importancia de traducir las onomatopeyas porque, aunque para ellos como Licenciados en Idiomas o conocedor de un idioma sean obvias, para los que no tienen dicho conocimiento no resultan obvias y pueden no entenderlas a pesar del contexto. Ejemplo:

-Ding dong (sonido de la campana en inglés) $\rightarrow$ Tolontolon (sonido de la campana en español).

Aunque también hay ciertas excepciones, puesto que la influencia del idioma es tal que su traducción estaría demás o no se entendería (En este caso el inglés). Ejemplo:

-Hahaha (risa en inglés) $\longrightarrow$ Jajaja (risa en español)

Es importante tener el conocimiento cultural tanto de la lengua meta como de la lengua origen para hacer la traducción adecuada y también para saber cuándo no es necesario hacerlo. Pero también puede suceder que, la onomatopeya no tenga el equivalente en la lengua meta, pero sí la tiene lo mejor es aplicarla.

Otro aspecto importante sobre las onomatopeyas es considerar el público al que se dirige el texto, puesto que debe adecuarse a ello, ya sea para adultos, niños, mujeres, jóvenes, etc.

Los jóvenes de la materia de traducción que imparte este profesor y traductor practicaron el uso y la aplicación de las onomatopeyas utilizando comics de Marvel tales como Ironman, los Vengadores, etc. Evidentemente tuvieron algunos problemas para traducir las onomatopeyas poco comunes, pero a pesar de ello, la mayoría de los alumnos logró traducir todas las onomatopeyas, aunque con ayuda del profesor, también hubo quienes las traducían sin tomar en cuenta el contexto o si era realmente necesario hacerlo. El inglés es uno de los idiomas más conocidos y hablados en el mundo, pero no tiene una gran variedad de onomatopeyas orales, la mayoría son escritas y poco comunes.

\section{DISCUSIÓN}

Con base en la investigación se puede decir que la cultura y el proceso de lexicalización de las onomatopeyas son factores imprescindibles para poder traducirlas del inglés al español. Para su apropiada comprensión, se deben seguir ciertas reglas de traducción y a su vez tener conocimiento de la formación de las onomatopeyas, es decir, su lexicalización. Aunque conocer este proceso es importante, es aún más necesario el conocimiento de la cultura de la lengua meta, pues esto da la 
Perspectivas Docentes 64

Interpretación y Representación de las Onomatopeyas en el Lenguaje Escrito al Momento de Traducir

Interpretation and Representation of Onomatopoeias in the Written Language when Translating

Claudia Cristel Salaya Custodio / Eleazar Morales Vázquez

pauta para hacer una traducción más fiel al sentido original que tenga la onomatopeya.

Existen estudios relacionados con las onomatopeyas japonesas, tales como Ruiz y Motoki (2015) e Inose (2009) que señalan la importancia que estos sonidos tienen especialmente en este idioma, y lo arraigado de su uso, debido a la falta de estudios en el que aborden el rol de las onomatopeyas del idioma inglés y su traducción al español.

Con la globalización y la mezcla de culturas se hace importante traducir las onomatopeyas para poder transmitir el sentimiento a las personas que no compartan el mismo código, o incluso saber cuándo no traducirlas, cuando su uso se ha extendido tanto que no es necesaria su traducción. Esa es la importancia de esta investigación, que busca resaltar las onomatopeyas como una parte clave del lenguaje oral, pero sobre todo escrito.

Finalmente es importante recalcar que el conocimiento de la cultura es importante para la apropiada interpretación y traducción de las onomatopeyas. Es decir, el traductor debe estar actualizado con lo que sucede día a día, pero, además, debe de conocer no solo su cultura sino también las expresiones culturales de todo el mundo. Actualmente los traductores tienen como una de sus herramientas el internet, el cual es muy útil ya que ayuda a conocer sobre las culturas de otros países sin tener que ir directamente a esos lugares. Sería de gran utilidad el diseño de materiales en línea tales como: blogs, foros de discusión y podcasts, ya que pueden ser de gran ayuda para consultar y comprender el uso correcto de las onomatopeyas.

\section{CONCLUSIÓN}

Las onomatopeyas son una parte muy importante del lenguaje oral y escrito, aunque las encontramos más en el lenguaje escrito, como en comics, historietas y cuentos. Estos sonidos son más comunes de lo que se piensa en nuestra vida diaria. Son tan poco estudiadas que la gramática no tiene una categoría para ellas, ignorando la importancia que éstas tienen en nuestro lenguaje. Sin tomar en cuenta que las onomatopeyas es lo que queda hoy en día de los orígenes del lenguaje, son estos sonidos los que no ayudan a comunicarnos entre nosotros y ayudaron a crear el lenguaje que hoy tenemos, ya sea inglés, español, japonés, etc., aunque todos los autores den pautas y consideren reglas para traducir las onomatopeyas, los traductores no siempre las respetan, sobre todo cuando son inexpertos y no tienen el suficiente conocimiento cultural. Pero esto también sucede debido a la globalización del idioma inglés, ya que como los lectores están tan adaptados a las onomatopeyas no es necesario traducirlas al español, porque ha llegado a suceder que no las entienden en su propio idioma porque no están adaptados a ellas. Para traducirlas se usa mayormente una técnica de traducción llamada adaptación, en virtud de ser totalmente culturales y hay que adaptarlas según su concepto. Otra razón por la que actualmente no se traducen las onomatopeyas es porque las historietas y comics son cada vez más elaborados, lo que complica la edición de la misma, y es difícil reproducir el formato de dibujo de una onomatopeya, por lo que resulta más fácil dejarlo como está. Pero la herramienta más importante para traducir las onomatopeyas, es sin duda, el amplio conocimiento de la cultura. 
Perspectivas Docentes 64

Interpretación y Representación de las Onomatopeyas en el Lenguaje Escrito al Momento de Traducir

Interpretation and Representation of Onomatopoeias in the Written Language when Translating

Claudia Cristel Salaya Custodio / Eleazar Morales Vázquez

\section{REFERENCIAS}

Bueno P. M. (2009) La onomatopeya y su proceso de lexicalización. Notas para el estudio.

Buron B. (s.f.) La onomatopeya, ¿mucho ruido para pocas nueces 0 un rompecabezas para el traductor? Université de Pau et des Pays de IAdour.

De la Cruz C. L. (2009) onomatopeyas inglesas en los tebeos españoles. Universidad de Alcalá Vol.4. España

Hernández S. C. (2003) Traductor y teoría de la traducción. Universidad de Valencia núm. 5 - año 2003. España

Inose, H. (2009) La traducción de onomatopeyas y mímesis japonesas al español y al inglés: los casos de la novela y el manga (Tesis Doctoral). Universidad de Granada. España

Jiménez B. R. (2010) El lenguaje no arbitrario: toponimia española. Universidad de la Rioja.

Joaquín M. (2013) 70 ejemplos de onomatopeyas. Recuperado de Un blog de Joaquín Moreno sobre recursos, literatura y ciencia ficción: https://jackmoreno.com/2013/06/08/ onomatopeyas/

Marín H. D. (2005) La especialización de la cultura y sus consecuencias en los estudios de traducción. Universidad de Málaga- TRANS-No9-. 2005. Sección 73-84.

Romeu A. J. (2012) Hablemos del lenguaje. VARONA Núm. 5.

Ruiz, D. y Motoki C. (2015) La singularidad de la onomatopeya japonesa en la lengua traducida y no traducida. Universidad de Salamanca.

Torres A. D. (2004) De interjecciones, onomatopeyas y paralingüismos en la celestina. Universidad de Chieti.

Torres S. M. (2000) Interjección y onomatopeya: bases para una delimitación pragmática. Universidad de Cádiz Vol.3

Torres S. M. A. y Barbeira G. J. L., (2003) Interjección y onomatopeya: bases para una delimitación pragmática. Universidad de Cádiz.

Wikilengua del español. (s. f). Onomatopeya. Recuperado de http://www.wikilengua.org/index.php/Onomatopeya. 